\title{
Giant peripheral ossifying fibroma with coincidental squamous cell carcinoma: a case report
}

\author{
Takeshi Karube' , Kanako Munakata', Yuka Yamada', Yuta Yasui' ${ }^{1}$, Shosuke Yajima', Nobuyuki Horie' , \\ Hiromasa Kawana ${ }^{2}$, Shuji Mikami ${ }^{3}$, Taneaki Nakagawa ${ }^{1}$ and Seiji Asoda ${ }^{{ }^{*}}$
}

\begin{abstract}
Background: Peripheral ossifying fibroma is an inflammatory or reactive hyperplasia of the gingiva that is usually small. It is formed by hard tissue in fibrous tissue, and the name "neoplastic lesion" has tended to be used frequently in Europe and America. Clinically, peripheral ossifying fibromas are painless, solitary, exophytic, sessile, or pedunculated and more frequently found in females than in males. To the best of our knowledge, there have been no reports of malignant cases. We herein report the case of giant peripheral ossifying fibroma with squamous cell carcinoma.
\end{abstract}

Case presentation: The patient was an 83-year-old Japanese woman who visited our hospital with a gingival massive mass. She was referred to us for an examination and treatment because it was difficult to perform tracheal intubation for surgery of sigmoid colon cancer at another hospital. The mass measured $83 \times 58 \times 35 \mathrm{~mm}$, and it protruded to the extra-oral region from the right maxillary premolar alveolar region. Panoramic $X$-ray revealed the shadow of the mass in the right maxillary premolar region, which included some hard tissue. Computed tomography showed scattering calcified images in the mass. Magnetic resonance imaging was not performed because she had vertebral artery clips and screws in her forehead. Given the above findings, we performed a biopsy under local anesthesia. However, we were unable to diagnose absolutely whether the dysplastic squamous epithelia were pseudocarcinomatous hyperplasia of the gingiva or well-differentiated squamous cell carcinoma. Therefore, tumor resection was performed under general anesthesia. The histopathological diagnosis was peripheral ossifying fibroma with coincidental squamous cell carcinoma. There have been no signs of recurrence during follow-up as of 2 years after surgery.

Conclusions: The etiology of giant peripheral ossifying fibroma with squamous cell carcinoma is still not definite. Therefore, careful observation is necessary. It needs to be examined by accumulation of more cases in the future. We herein report the case of giant peripheral ossifying fibroma coincidental squamous cell carcinoma.

Keywords: Peripheral ossifying fibroma, Oral squamous cell carcinoma

\section{Background}

Peripheral ossifying fibroma (POF) is an inflammatory or reactive hyperplasia of the gingiva and presents clinically as a painless, slowly growing mass. POF occurs more

*Correspondence: asoda@keio.jp

${ }^{1}$ Department of Dentistry and Oral Surgery, Keio University School of Medicine, 35 Shinanomachi, Shinjuku-ku, Tokyo, Japan

Full list of author information is available at the end of the article frequently in females than in males [1-3], especially female patients in the second or third decade of life [3, 4], and is more common in the anterior maxilla than in other locations $[5,6]$. POFs are generally smaller than $<2 \mathrm{~cm}$ in size [7-9]. However, larger lesions have been rarely reported in the literature $[8,10]$. Notably, there have been no reports of POF with coincidental squamous cell carcinoma. We herein report a long-term case of giant POF with coincidental squamous cell carcinoma. original author(s) and the source, provide a link to the Creative Commons licence, and indicate if changes were made. The images or other third party material in this article are included in the article's Creative Commons licence, unless indicated otherwise in a credit line to the material. If material is not included in the article's Creative Commons licence and your intended use is not permitted by statutory regulation or exceeds the permitted use, you will need to obtain permission directly from the copyright holder. To view a copy of this licence, visit http://creativecommons.org/licenses/by/4.0/. The Creative Commons Public Domain Dedication waiver (http://creativeco mmons.org/publicdomain/zero/1.0/) applies to the data made available in this article, unless otherwise stated in a credit line to the data. 


\section{Case presentation}

In 2017, an 83-year-old Japanese woman presented to our department with a chief complaint of a mass in her right maxillary premolar region. She had initially noticed a painless mass in her right maxillary premolar region in 2002. After she had first noticed of the mass, it grew gradually in size, but she sought no treatment for it. She was referred to us for examination and treatment because it was difficult to perform tracheal intubation for surgery of sigmoid colon cancer at another hospital. Her history included sigmoid colon cancer, subarachnoid hemorrhaging, bronchitic asthma, and cardiac insufficiency. Regarding the intra- and extra-oral findings, a massive pedunculated mass in the right maxillary premolar region measuring $83 \times 58 \times 35 \mathrm{~mm}$ was palpable (Fig. 1). Furthermore, it covered the front of the right palate, and it protruded to the extra-oral region from the right maxillary premolar alveolar region. Its surface was almost entirely smooth, and some erosions and ulcerations were seen. It was elastic and hard and showed no tenderness on palpation. There was no palpable regional lymphadenopathy, and a laboratory examination revealed no abnormal values.

Panoramic X-ray revealed the shadow of the mass in the right maxillary premolar region, which included some hard tissue (Fig. 2). Computed tomography (CT) showed scattering calcified images in the mass (Fig. 3). Magnetic resonance imaging was not performed because she had vertebral artery clips and screws in her forehead. Given the above findings, we suspected benign gingival tumor in the right maxillary premolar region and performed a biopsy under local anesthesia (Fig. 4a, b).

Histologically, proliferation of dysplastic squamous epithelia was observed (Fig. 5). We noted subepithelial mild dysplastic spindle-shaped cells and collagenous

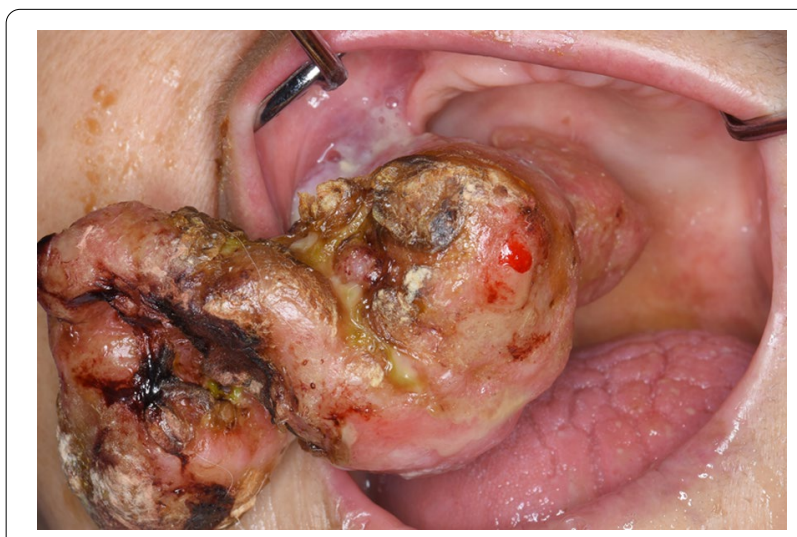

Fig. 1. Intra- and extra-oral findings. A massive pedunculated mass in the right maxillary premolar region is observed. It protrudes to the extra-oral region from the right maxillary premolar alveolar region

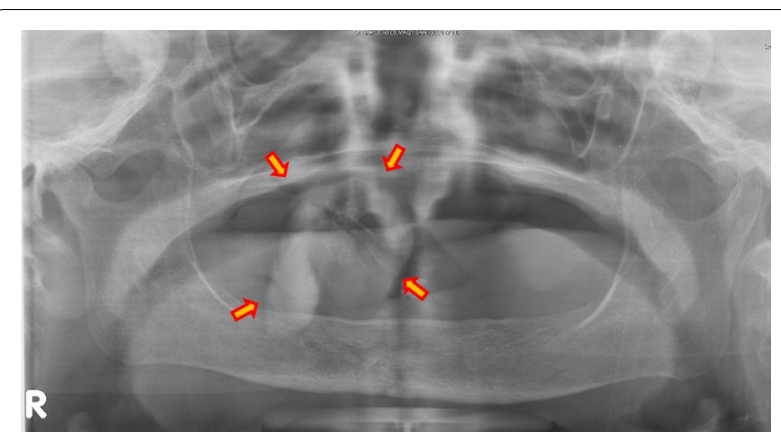

Fig. 2. Panorama $X$-ray photograph revealing the shadow of the mass in the right maxillary premolar region, which includes some hard tissues (arrows)

fibers, and scattered calcification and ossification were also observed (Fig. 5). Immunohistochemically, the spindle cells were negative for pan-cytokeratin (AE1/AE3), and nuclear translocation of $\beta$-catenin was not observed in the spindle cells (data not shown). Therefore, we excluded a diagnosis of carcinosarcoma and fibromatosis. However, we were unable to diagnose absolutely whether the dysplastic squamous epithelia were pseudocarcinomatous hyperplasia of the gingiva or well-differentiated squamous cell carcinoma. In addition, positron emission tomography with computed tomography (PET/CT) revealed that the maximum standard unit value (SUV$\max$ ) of the sigmoid colon and the oral lesion were 15.27 and 14.99, respectively, and there were no other obvious metastases (Fig. 6). Therefore, we performed tumorectomy under general anesthesia. The pedicle of the tumor was located at the right maxillary premolar area, and the tumor-including the tissue surrounding the lesionwas resected as one mass together with the periosteum (Fig. $7 \mathrm{a}-\mathrm{d}$ ). At that time, partial destruction of the maxillary bone was seen. The exposed bone surface was slightly curetted. After resection, the wounded area was covered with artificial dermis (TERDERMIS). Finally, tieover dressing by gauze with ointment was performed.

The microscopic findings of the surgically removed tumor were similar to those of the biopsy specimen. The body of the tumor was composed of spindle-shaped cells that were proliferating with collagenous fiber, and scattered bone formation was also observed (Fig. 8). The destruction of the basement membrane by atypical squamous epithelia was observed in the surgically removed specimen, suggesting stromal invasion. In addition, immunohistochemical analysis revealed that the dysplastic squamous epithelia were positive for Ki67 and CK17, suggesting that they were squamous cell carcinoma, not pseudocarcinomatous hyperplasia. Furthermore, some spindle cells were positive for smooth muscle action 

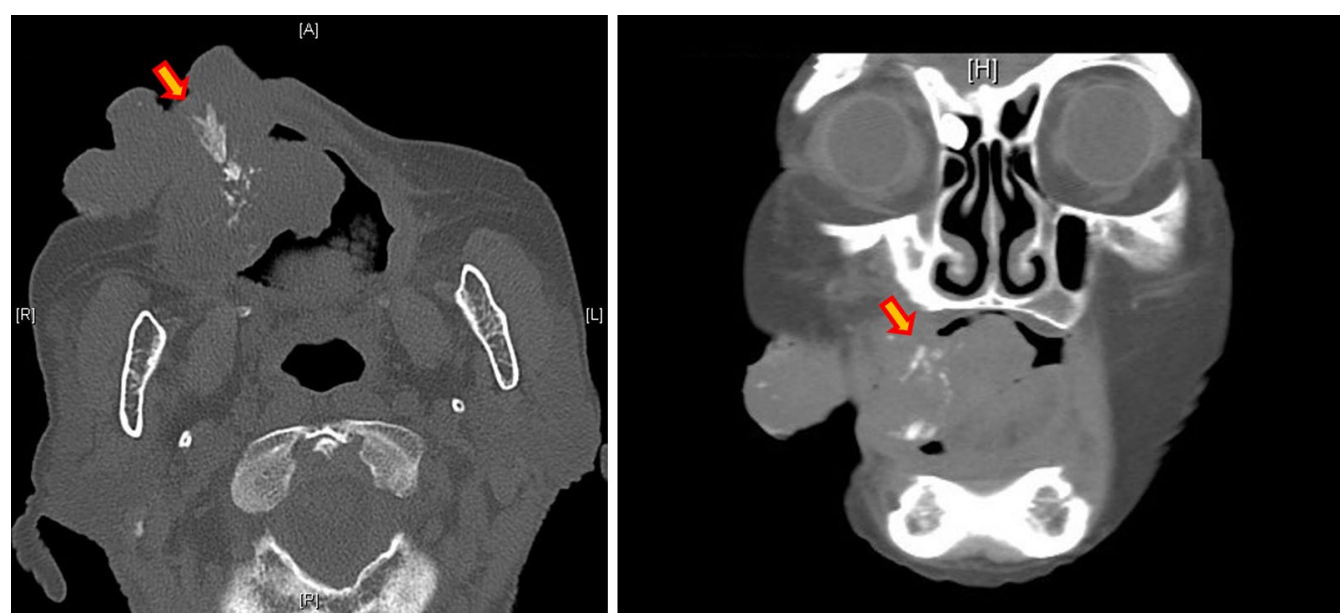

Fig. 3. Computed tomography showing scattering calcified images in the mass (arrows)
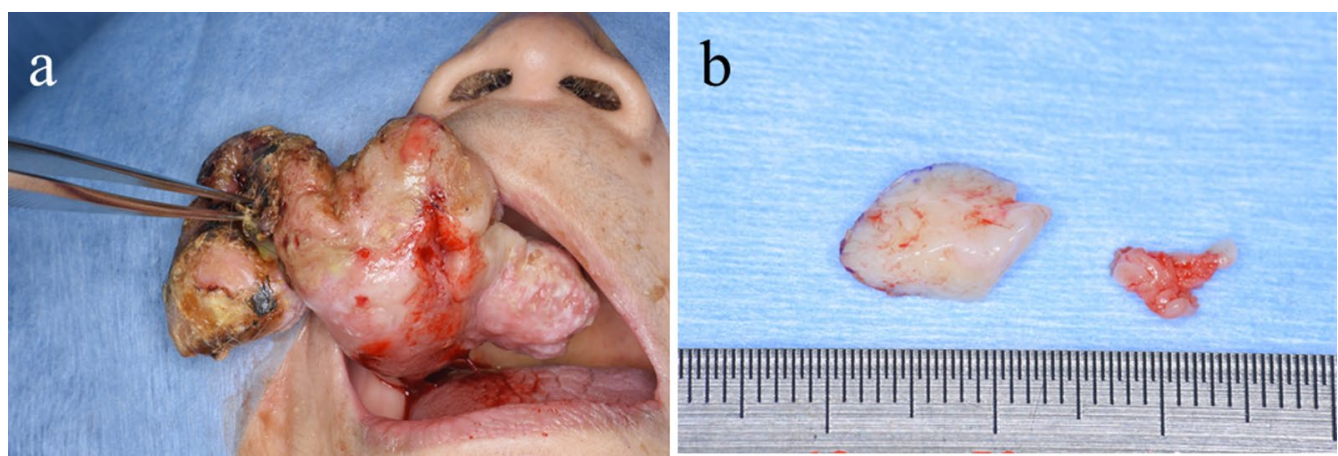

Fig. 4. Operative findings from the biopsy. a Extraoperative photograph, b excised specimen

(SMA), indicating myofibroblastic differentiation. Therefore, the epithelial component of the tumor was considered to be well-differentiated squamous cell carcinoma. Because most of the tumor was occupied by spindleshaped cells and marked ossification histopathologically, we diagnosed the tumor as POF with squamous cell carcinoma (pT1NOM0).

One week after surgery, we removed the gauze and covered the wound with an oral appliance for protection (Fig. 9a, b). There have been no signs of local recurrence or metastasis during follow-up as of 2 years after surgery.

\section{Discussion and conclusions}

Exophytic gingival lesions consisting of cellular myofibroblast proliferation, including calcification [11, 12], have been described in the literature since the late 1940s. Various designations have been given to similar lesions, such as epulis, peripheral fibroma with calcification, and POF. They account for 3\% of all oral tumors and 9.6\% of all gingival lesions [12-14]. Among these, POF is a benign mesenchymal lesion, and Gardner [15] reinforced the notion that POF is not a peripheral variant of central ossifying fibroma, which is a true neoplasm but a distinct non-neoplastic inflammatory proliferation. Although the etiology and pathogenesis of POF remain unknown, it seems commonly to be a reactive condition and originate from cells in the periodontal ligament, probably related to trauma or local irritants $[12,14,16,17]$. In our case, the patient probably still had a tooth at the time the mass developed. However, it is thought that she subsequently lost all of her teeth as she aged, thus resulting in the edentulous condition. Sacks et al.[10] also reported a case of giant POF in an edentulous patient. He noted that an edentulous state provided no resistance to the lesion's proliferation. On the other hand, some authors have suggested that POFs are related to hormonal changes $[1,2$, 18]. POF is usually small with an anterior maxillary presentation [5, 6]. It includes hard tissue in fibrous tissue, and the name "neoplastic lesion" has tended to be used frequently in Europe and America. Clinically, POFs are 

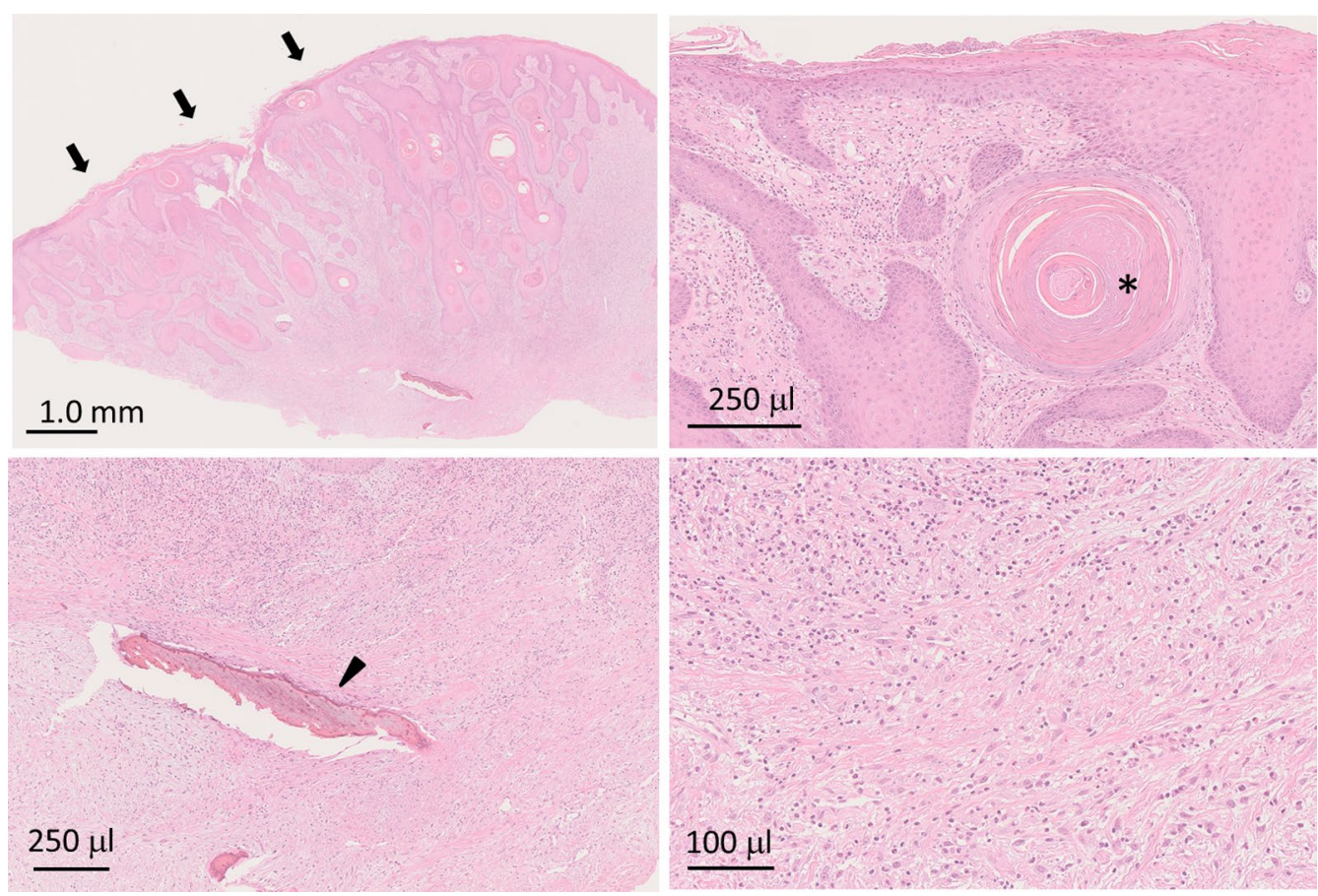

Fig. 5. Histopathological findings (hematoxylin-eosin stain). The biopsy specimen was composed of dysplastic spindle-shaped epithelia (arrows) and stromal tissue. Some ossification (arrow head) and cancerous pearl formation (asterisk) are observed. High-magnification view of stromal tissue revealed spindle-shaped stromal cells with collagenous fiber (lower right figure)
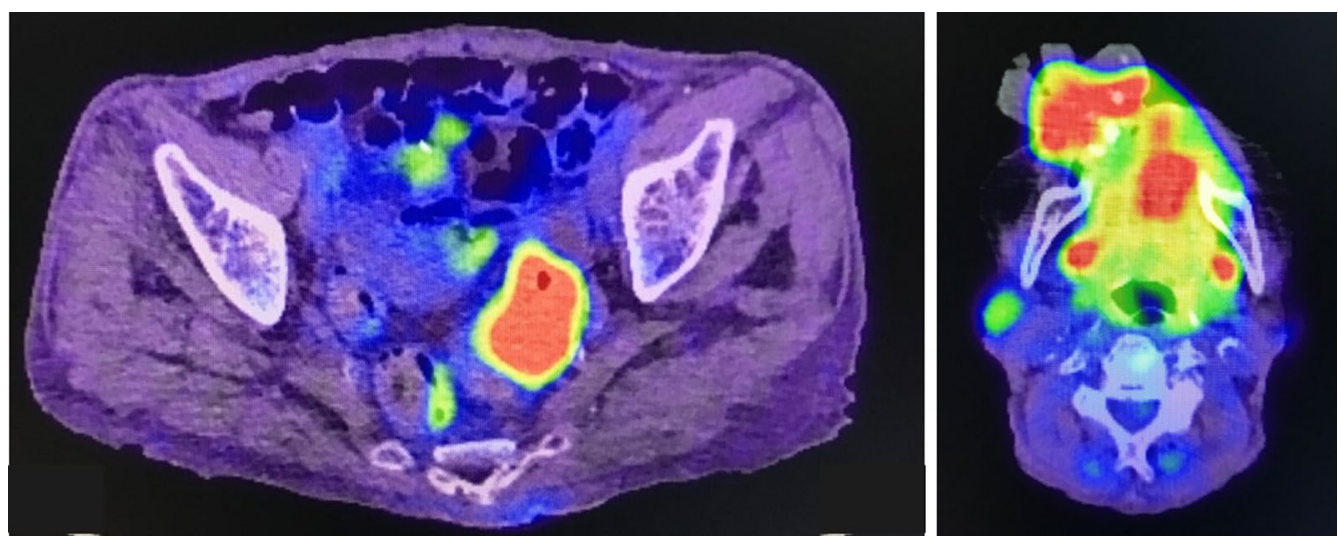

Fig. 6. PET/CT reveals that the SUVmax of the sigmoid colon is 15.27, and that of the oral lesion is 14.99. There are no other obvious metastases

painless, solitary, exophytic, sessile, or pedunculated and more frequently found in females than in males [1-3], especially female patients in the second or third decade of life $[3,4]$. In our case, the tumor was found in an elderly woman and was neglected for 14 years owing to the painless nature of the mass, which showed exophytic enlargement in the base of maxillary premolar region. Regarding radiographic evaluations, the presence of radiopacity, which is observed in soft tissues, represents the synthesis of bone (mature or immature), cementum, or calcifications, in various proportions. Immature woven bone is the most common type of such mineralization, but mature lamellar bone is seen as a form of maturation of the lesion. The present case included a large amount of mature bone, as the lesion had grown over a period of 14 years.

Histopathologically, POFs have a mineralized mass surrounded by a stroma of fibrocellular connective tissue. 

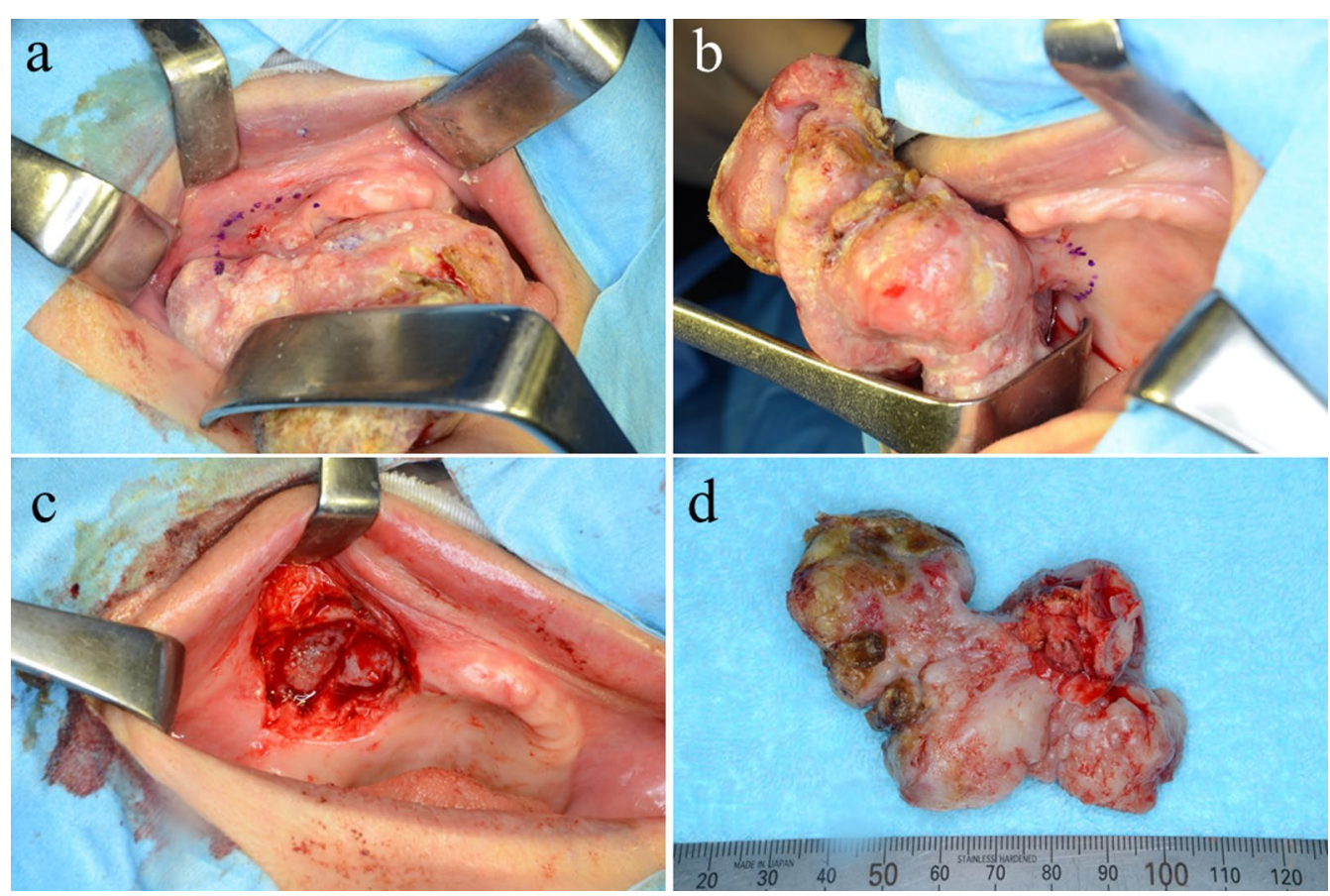

Fig. 7. Operative findings. $\mathbf{a}, \mathbf{b}$ The excision range was set with a safety margin of approximately $1 \mathrm{~cm}$ around the tumor. $\mathbf{c}$ Postoperative site of lesion. d Resected specimen

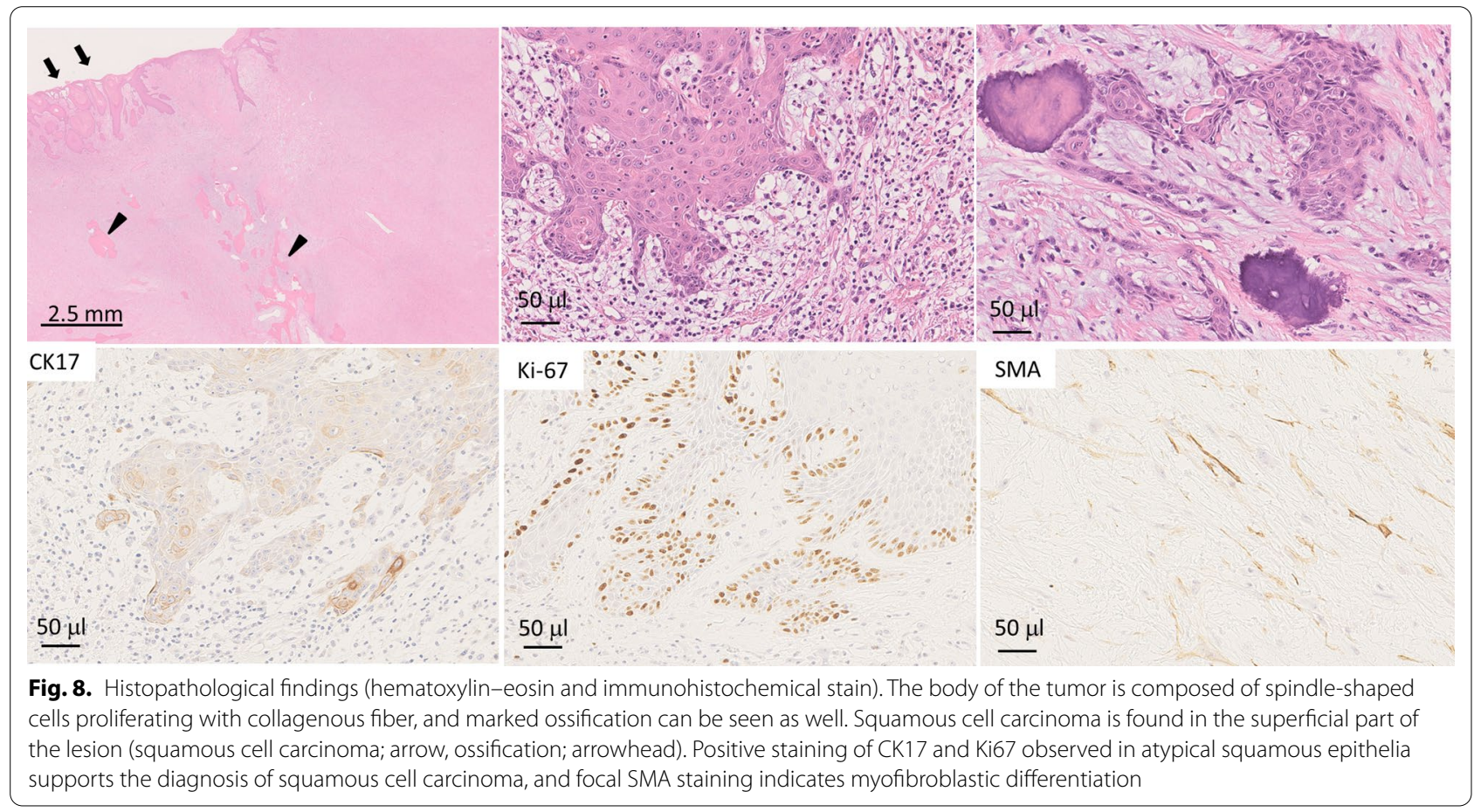

The definitive diagnosis depends on the results of the microscopic evaluation, especially with regard to the presence of bone or calcified materials as the key feature
[11]. The hard tissues formed in POF are classified into trabecular bone, compact bone, lamellar bone, cementicles or ossicles, and dystrophic calcification [19-21]. 

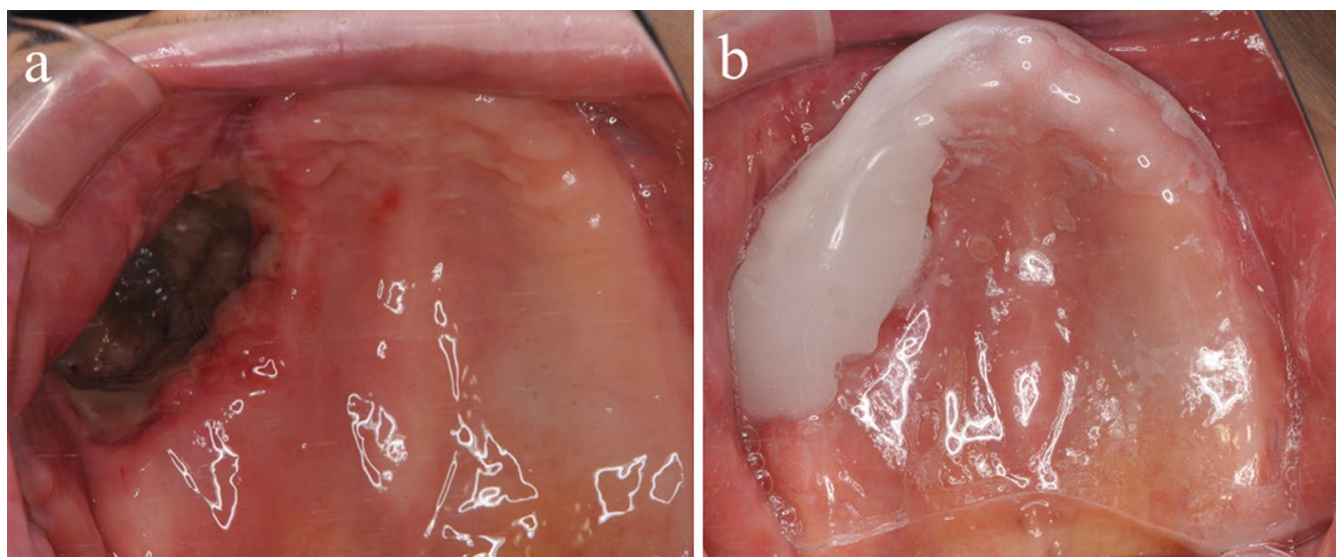

Fig. 9. Clinical follow-up. a Seven days' follow-up showing partial wound healing. b Covering with an oral appliance for protection

In most cases, there is a mixture of these components. However, there are various theories regarding the origin of hard tissue formation, and no unified view has yet been obtained.

The immunohistochemical profile of POF has been poorly documented [4]. Some authors have already made use of anti-muscle actin antibody in their studies. For example, Marcos et al. [4] described four cases of POF, and their findings support a fibroblastic-myofibroblastic origin of the lesion, thus aiding in its differential diagnosis. In addition, Lázare et al.[22] used a panel of antibodies in 26 specimens that stained for smooth muscle actin in the spindle cell component in most cases and confirmed the myofibroblastic nature of the lesion. We used a panel of antibodies in the present specimen, which stained for smooth muscle actin in the spindle cell component. An imbalance in the structural and signaling properties of $\beta$-catenin often results in disease and deregulated growth connected to cancer and metastasis. In our case, the spindle cells were actin-positive and keratinnegative, suggesting that some of them had differentiated into myofibroblasts. However, since there was no nuclear migration of catenin, it was interpreted as reactive rather than fibromatosis.

The size of POF is often $10-20 \mathrm{~mm}[7,9]$. However, some lesions grow to more than $20 \mathrm{~mm}$ in size. Generally, POF grows slowly, and in today's environment of strong investment in oral hygiene, it is extremely rare for them to grow to such a large size without resection. Some authors have occasionally described relatively large lesions in case reports of POF $[8,10,23]$. Although the most common site of POF is the anterior maxillary gingival area, there are few reports of it growing very large in the same region [10, 23, 24]. This is considered to be because the anterior area is easy to observe, and importance is attached to aesthetics, so treatment tends to be performed before the mass becomes large. Regarding the physiological function of the oral cavity, the tongue pressure is greater than the lip and buccal pressure, so the lesion seemed to have become relatively large and protruded from the oral cavity in our case. Giant POFs have several common clinical features, including large, atypical dimensions that may cause facial asymmetry and teeth displacement with no root resorption. Ectopic eruption, migration, and separation of teeth have been reported, as well as bone destruction [8, 24-26]. In our case, bone destruction was seen, although the patient was edentulous. Furthermore, giant lesions can impair speech, chewing, swallowing, aesthetics, and mouth closing. Similar to our case, most giant POFs are diagnosed in older adults [10, 24, 25]. Interestingly, while conventional POFs are more prevalent in females than in males, the giant type shows no sex predilection. Regarding the clinical appearance, giant POF commonly presents as an exophytic mass that can develop an ulcerated surface due to contact with the teeth on the opposite side of the mouth. The most common site of giant POF is the posterior mandible, although our present case does not fit this pattern description.

The treatment of POF requires total resection, including the periosteum and periodontal ligament, as well as all local etiological factors. Since recurrence can result from incomplete resection or failure to section the periodontal ligament, accurate resection is also required. The recurrence rate of POF is considered to be relatively high, ranging from $8 \%$ to $20 \%[9,27]$. Thus, strict postoperative follow-up is necessary to detect early recurrence. Although most literature supports the notion that the periodontal ligament is the origin of the lesion [12, $14,16,17,22]$, there are reports of POF in edentulous patients aside from the present patient $[1,10]$. 
Whether POF is a true neoplasm or a reactive proliferation is unclear. Therefore, POF is not included in the World Health Organization (WHO) 2017 Classification of Head and Neck Tumors. POF contains variable proportions of inflammatory cells, such as lymphocytes. Interestingly, although some giant POFs are characterized as neoplastic growths, to our knowledge, there have been no cases of POF with coincidental squamous cell carcinoma except for the present case. Because POF is a mesenchymal tumor, it was speculated that the squamous cell carcinoma in this case may have been caused by trauma as POF or may have been the result of exposure of the mucosa to ultraviolet rays from the sun or other stimulant. As for metastasis, the sigmoid colon carcinoma was an adenocarcinoma, and the oral lesion was a squamous cell carcinoma, suggesting that there was no mutual metastasis. In our case, immunohistochemical staining revealed partial p53 positivity (data not shown) as well as CK17 and Ki67 positivity. Moreover, hematoxylin-eosin staining also showed squamous cell carcinoma morphologically. However, the etiology of giant POF with squamous cell carcinoma is still not definite, and needs to be examined by accumulation of more cases in the future.

\section{Abbreviations}

POF: Peripheral ossifying fibroma; CT: Computed tomography; PET/CT: Positron emission tomography with computed tomography.

\section{Acknowledgements}

We thank JMC (www.japan-mc.co.jp) for English language editing.

\section{Authors' contributions \\ $T K, K M, Y Y, Y Y, S Y, N H$, and SA treated the patient. TK, KM, and SA drafted the manuscript. HK and TN critically revised the manuscript for important intel- lectual content. Pathological diagnosis was made by SM. All authors read and approved the final manuscript.}

\section{Funding}

This case report was not funded.

\section{Availability of data and materials}

The datasets created during and/or analyzed during this case are available from the corresponding author on reasonable request.

\section{Declarations}

Ethics approval and consent to participate

Not applicable.

\section{Consent for publication}

Written informed consent was obtained from the patient for publication of this case report and any accompanying images. A copy of the written consent is available for review by the Editor-in-Chief of this journal.

\section{Competing interests}

The authors declare that they have no competing interests.

\section{Author details}

${ }^{1}$ Department of Dentistry and Oral Surgery, Keio University School of Medicine, 35 Shinanomachi, Shinjuku-ku, Tokyo, Japan. ${ }^{2}$ Department of Oral and Maxillofacial Implantology, Kanagawa Dental University, Yokosuka, Japan.
${ }^{3}$ Division of Diagnostic Pathology, Keio University School of Medicine, Tokyo, Japan.

Received: 9 February 2021 Accepted: 8 November 2021

Published online: 19 December 2021

\section{References}

1. Kumar SK, Ram S, Jorgensen MG, Shuler CF, Sedghizadeh PP. Multicentric peripheral ossifying fibroma. J Oral Sci. 2006:48:239-43.

2. Walters JD, Will JK, Hatfield RD, Cacchillo DA, Raabe DA. Excision and repair of the peripheral ossifying fibroma: a report of 3 cases. J Periodontol. 2001;72:939-44

3. Yadav R, Gulati A. Peripheral ossifying fibroma: a case report. J Oral Sci. 2009;51:151-4.

4. García de Marcos JA. Peripheral ossifying fibroma: a clinical and immunohistochemical study of four cases. J Oral Sci. 2010;52:95-9.

5. Kenney JN, Kaugars GE, Abbey LM. Comparison between the peripheral ossifying fibroma and peripheral odontogenic fibroma. J Oral Maxillofac Surg. 1989;47:378-82.

6. Zhang W, Chen Y, An Z, Geng N, Bao D. Reactive gingival lesions: a retrospective study of 2,439 cases. Quintessence Int. 2007;38:103-10.

7. Stafne EC. Peripheral fibroma (epulis) that contains a cementum-like substance. Oral Surg Oral Med Oral Pathol. 1951:4:463-5.

8. Poon CK, Kwan PC, Chao SY. Giant peripheral ossifying fibroma of the maxilla: report of a case. J Oral Maxillofac Surg. 1995;53:695-8.

9. Farquhar T, Maclellan J, Dyment H, Anderson RD. Peripheral ossifying fibroma: a case report. J Can Dent Assoc. 2008;74:809-12.

10. Sacks HG, Amrani S, Anderson K. "Gigantiform" peripheral ossifying fibroma: report of a case. J Oral Maxillofac Surg. 2012;70:2610-3.

11. Poonacha KS, Shigli AL, Shirol D. Peripheral ossifying fibroma: a clinical report. Contemp Clin Dent. 2010;1:54-6.

12. Verma E, Chakki AB, Nagaral SC, Ganji KK. Peripheral cementoossifying fibroma: case series literature review. Case Rep Dent. 2013;2013(1):930870.

13. Chatterjee A, Ajmera N, Singh A. Peripheral cemento-ossifying fibroma of maxilla. J Indian Soc Periodontol. 2010;14:186-9.

14. Dahiya P, Kamal R, Saini G, Agarwal S. Peripheral ossifying fibroma. J Nat Sci Biol Med. 2012;3:94-6.

15. Gardner DG. The peripheral odontogenic fibroma: an attempt at clarification. Oral Surg Oral Med Oral Pathol. 1982;54:40-8.

16. Cuisia ZE, Brannon RB. Peripheral ossifying fibroma-a clinical evaluation of 134 pediatric cases. Pediatr Dent. 2001;23:245-8.

17. Luvizuto ER, Da Silva JB, Luvizuto GC, Pereira FP, Faco EF, Sedlacek P, Poi WR. Peripheral ossifying fibroma. J Craniofac Surg. 2012;23:e7-10.

18. Moon WJ, Choi SY, Chung EC, Kwon KH, Chae SW. Peripheral ossifying fibroma in the oral cavity: CT and MR findings. Dentomaxillofac Radiol. 2007;36:180-2.

19. Bhaskar SN, Jacoway JR. Peripheral fibroma and peripheral fibroma with calcification: report of 376 cases. J Am Dent Assoc. 1966;73:1312-20.

20. Buchner A, Ficarra G, Hansen LS. Peripheral odontogenic fibroma. Oral Surg Oral Med Oral Pathol. 1987;64:432-8.

21. Zain RB, Fei YJ. Fibrous lesions of the gingiva: a histopathologic analysis of 204 cases. Oral Surg Oral Med Oral Pathol. 1990;70:466-70.

22. Lazare H, Peteiro A, Perez Sayans M, Gandara-Vila P, Caneiro J, Garcia-Garcia A, Anton I, Gandara-Rey JM, Suarez-Penaranda JM. Clinicopathological features of peripheral ossifying fibroma in a series of 41 patients. Br J Oral Maxillofac Surg. 2019:57:1081-5.

23. Reddy V, Kv A, Wadhwan V, Venkatesh A. Giant peripheral ossifying fibroma of the posterior mandible_-a rare case report. Iran J Pathol. 2017;12:397-401.

24. Childers EL, Morton I, Fryer CE, Shokrani B. Giant peripheral ossifying fibroma: a case report and clinicopathologic review of 10 cases from the literature. Head Neck Pathol. 2013;7:356-60.

25. Célio-Mariano R, Oliveira M, de Carvalho Silva A. Large peripheral ossifying fibroma: clinical, histological, and immunohistochemistry aspects. A case report. Rev Esp Cir Oral Maxilofac. 2017;39:39-43.

26. Freire AEN, da Silva VSA, Pereira AAC, Ribeiro Junior NV, de Carli ML, Sperandio FF, Hanemann JAC. Giant peripheral ossifying fibroma treated 
with piezosurgery and platelet-rich fibrin: a rare case report. Clin Adv Periodontics. 2019;9:15-9.

27. Trasad VA, Devarsa GM, Subba Reddy VV, Shashikiran ND. Peripheral ossifying fibroma in the maxillary arch. J Indian Soc Pedod Prev Dent. 2011;29:255-9.

\section{Publisher's Note}

Springer Nature remains neutral with regard to jurisdictional claims in published maps and institutional affiliations.

- fast, convenient online submission

- thorough peer review by experienced researchers in your field

- rapid publication on acceptance

- support for research data, including large and complex data types

- gold Open Access which fosters wider collaboration and increased citations

- maximum visibility for your research: over 100M website views per year

At $\mathrm{BMC}$, research is always in progress.

Learn more biomedcentral.com/submissions 